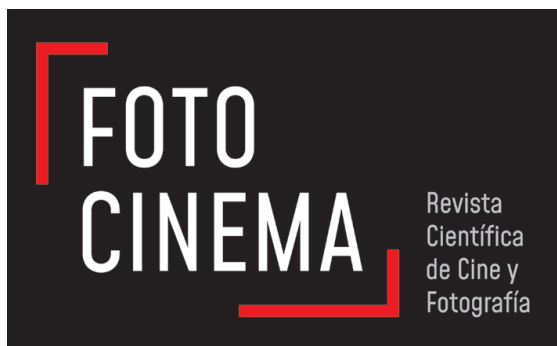

FOTOCINEMA, n²2 (2021) || E-ISSN: 2172-0150

\title{
Simulacro y juego. La imagen-exceso cinematográfica como reflejo de una sociedad hiperreal
}

\section{Simulacrum and game. The cinematographic image-excess as a reflection of a hyperreal society}

\author{
Carlos Rojas-Redondo \\ Universidad Internacional de la Rioja, España \\ carlos.rojas@unir.net \\ https://orcid.org/o000-0001-9423-5.510 \\ Paco Lara-Barranco \\ Universidad de Sevilla, España \\ paco_lara@us.es \\ https://orcid.org/oooo-0002-7148-4095
}

\section{Resumen:}

El presente estudio aborda el concepto de la "imagen-exceso" (Lipovetsky y Serroy, 2009), un recurso cinematográfico que consigue introducir al espectador en una sucesión vertiginosa de escenas visuales hiperespectaculares. Es a partir de la extraordinaria evolución tecnológica de las últimas décadas cuando las creaciones digitales (realidades virtuales) han generado imágenes en el cine que llegan a competir con la realidad, solapándola y haciendo compleja su diferenciación para el receptor. En el texto abordamos el papel determinante que el simulacro y el juego ejercen al ser motores clave para la construcción de esa imagen-exceso, que se establece entre parámetros virtuales de características neobarrocas y sublimes. Por tanto, nos adentraremos en conocer cómo el simulacro se desarrolla en el ámbito del cine, y cómo el juego va desplegando todo su potencial para actuar en la mente del espectador con el firme propósito de inducirle a una hiperrealidad, la metarrealidad que el propio cine supone. Aunque algunas producciones cinematográficas presentan la limitación conocida como uncanny valley al producir un rechazo de credibilidad en el observador, nuestra principal conclusión subraya la necesidad de atracción que ha de suscitar la imagen-exceso para que el simulacro y el juego hagan acto de presencia.

\begin{abstract}
:
The present study addresses the concept of the "image-excess" (Lipovetsky \& Serroy, 2009), a cinematographic resource that manages to introduce the viewer into a dizzying succession of hyperspectacular visual scenes. It is from the extraordinary technological evolution of the last decades when digital creations (virtual realities) have generated images in the cinema that come to compete with reality, overlapping it and making its differentiation complex for the receiver. In the text we address the determining role that simulation and game play as they are key drivers for the construction of that image-excess, which is established between virtual parameters of neo-baroque and sublime characteristics. Therefore, we will delve into knowing how the simulation develops itself in the field of cinema, and how the game unfolds its full potential to act in the mind of the viewer with the firm intention of inducing him to a hyperreality, the meta-reality that cinema supposed. Although some cinematographic productions present the limitation known as uncanny valley by producing a rejection of credibility in the observer, our main conclusion underlines the need for attraction that the excess-image must arouse, so that simulacrum and game make an appearance.
\end{abstract}

Palabras clave: Cine; simulacro; juego; creación digital; valle inquietante; imagenexceso.

Keywords: Cinema; Simulacrum; Game; Digital Creation; Uncanny Valley; ImageExcess 


\section{Introducción}

Este artículo pretende contribuir al estudio de la "imagen-exceso", un recurso cinematográfico que logra imbuir al espectador en un desarrollo narrativo de características visuales hiperespectaculares. La “imagen-exceso” (Lipovetsky y Serroy, 2009), definida por los "extremos" - en cuanto a escenografías barrocas, ritmo narrativo acelerado, exaltación de la violencia, saturación sonora y larga duración temporal, como técnicas cinematográficas más habituales-, se deriva de los grandes cambios tecnológicos y de sus influencias en la construcción de la sociedad actual hipermoderna (Lipovetsky y Charles, 2014) y saturada (Gergen, 1992) en la que vivimos. ¿Qué mecanismos actúan en la imagen-exceso para producir un impacto en la percepción del espectador? A partir de estudios pioneros sobre la imagen-exceso del cine, nuestra investigación pone el foco en el papel que ejercen el simulacro y el juego al ser generadores de la metarrealidad proyectada desde la pantalla. El simulacro (Baudrillard, 2005), explora las particularidades de la imagen cinematográfica cuando esta se vuelve ante al observador totalmente creíble y real, frente a la incredulidad - siempre latente- y la superficialidad de su artificio. Considerado como pareja inseparable del simulacro, el juego (Gadamer, 1988, Huizinga, 2012) anima la creación de la metarrealidad citada gracias a sus capacidades/posibilidades de comprensión que ofrece al espectador para introducirle en las reglas que el cine despliega. Es con la interrelación de ambos conceptos cuando acontece el poder de seducción de la imagen-exceso creada que, en competencia directa con la realidad misma, trata de atrapar al espectador para hacerle más creíble el relato expuesto. Si bien el estudio viene a resaltar la importancia del perfecto engranaje que ha de forjarse entre el poder de la imagen y su capacidad de engaño y creencia, para que el simulacro y el juego absorban al espectador a una nueva hiperrealidad, nuestro análisis no pasa por alto una gran limitación de la imagen-exceso, denominada "uncanny valley" (Masahiro Mori, 1970). El "valle inquietante", en su traducción al castellano, refiere a los déficits de credibilidad en la recreación de escenografías y particularmente de caracterización de personajes antropomórficos principales. Limitaciones virtuales que 
evidencian algunas carencias de la imagen-exceso en cuanto a la simulación y al desplazamiento de la realidad del espectador al introducirse en la película.

Finalmente, para llevar a cabo el estudio, hacemos uso de una metodología analítico-comparativa e inductiva, sustentadas en estudios previos destacables. Con ello, hemos pretendido arrojar luz al objeto de estudio evitando los razonamientos en exceso simplistas del momento hiperreal en el que vivimos y tratando de pensar, de manera compleja, los mecanismos sobre los que se construye la imagen-exceso del cine.

\section{El simulacro en la imagen cinematográfica}

¿Qué cambios observamos en la actualidad entre la relación imagen cineespectador desde la aparición del cine en color en la gran pantalla? Un acontecimiento que tuvo lugar con la película iSigamos con el espectáculo! (On with the Show!, Alan Crosland, 1929). ¿Afrontamos las imágenes de igual forma en la era digital? ¿De qué manera interviene el tiempo en este binomio? Hoy, es inevitable vivir alejado de las imágenes así como de la influencia de estas. La vida se ha transformado en una existencia a través de una pantalla que no cesa de producir millones de imágenes por segundo, inquietando la realidad que habitamos. La gran evolución tecnológica de las últimas décadas nos ha empujado a concebir nuestra existencia aceleradamente, alterando nuestras costumbres y haciendo del espacio únicamente una distancia reducida a un tiempo. Este hecho provoca que la analogía entre espacio y tiempo repercuta en los diversos modos o formas de comunicación que experimentamos, lo que condiciona a nuestras relaciones personales y a los vínculos que generamos con los dispositivos que manejamos. No percibimos y no nos movemos de igual manera en el mundo actual a cómo se producía tiempo atrás, de ahí que Román Gubern exponga:

El desarrollo de nuestra iconosfera creció paralelamente al incremento de las tasas de velocidad en la vida urbana. Se ha estimado, por ejemplo, que en la época de Lautrec un peatón concedía veinte segundos al examen de un cartel, pero en 1960 se calculaba que su atención no superaba los dos segundos (Gubern, 1996, p. 122). 
Disponer de un determinado tiempo para dilucidar con tranquilidad qué se esconde tras las imágenes en el cine postmoderno se ha convertido en ardua tarea ya que nuestra apresurada vida nos empuja a acciones de ritmo frenético, sonidos incesantes y cambios de plano continuos, atisbando un cine independiente o vanguardista imposible de soportar. La lentitud nos aburre e impacienta, lo queremos todo 'aquí y ahora', y eso ha cambiado la relación del espectador con el cine. Películas como Pasaia Bitartean (Irati Gorostidi, 2016), donde visualizar de manera documental cómo se estructura el entramado urbano y pensar la ciudad y sus espacios se transforma en un relato lento de admiración paisajística, o La mano invisible (David Macián, 2016), con un ritmo constante y repetitivo nos enfrenta al mundo de la precariedad laboral a modo de reality show, pueden sobrepasar altamente las expectativas de cine comercial y provocar un choque en el espectador de cansancio, disgusto o incomprensión.

Por tanto, descomponer esa "imagen-tiempo", de la que hablaba el filósofo francés Gilles Deleuze, se comprende fundamental dado que las relaciones del espectador con el cine han cambiado por las innovaciones tecnológicas y la génesis de nuevos lazos de unión, lo que implica cambios en la manera de pensar y afrontar las imágenes que componen nuestro mundo. Toda imagen es símbolo de inmediatez e instantaneidad que pretende dejar una huella, siempre evidenciada por la muestra de aquello que se desvanece, que desaparece. La imagen en el cine busca, en palabras de Nicolás Bourriaud, atribuidas a la obra de arte, "la posibilidad de establecer nuevas relaciones" (Quintana, 2011, p. 164) y de dar sentido a un mundo descrito por su falta de clarividencia. En ocasiones, la imagen adquiere un poder de significación y sentido más allá de la simple lectura lineal como es el caso de los sensogramas. Definidos por Gubern como "representaciones ideográficas autónomas, que utilizan generalmente significantes icónicos para expresar sensaciones, estados de ánimo o vivencias psicológicas de un actante", que tratan de adjetivar al sujeto y otorgarle un carácter activo tras descifrar los códigos que contiene y que llevará a Umberto Eco a denominarlo como "metáforas visualizadas" (Gubern, 1996, pp. 100-103). Un recurso retórico y simbólico muy vinculado al género del cómic- que se hace presente en el cine a través 
de la composición de planos como la erupción de un volcán que sirven de símbolo para la fusión sexual de dos personas. En la película El amor es el demonio: Estudio para un retrato de Francis Bacon (Love Is the Devil: Study for a Portrait of Francis Bacon, John Maybury, 1998) observamos la transformación del espacio y del tiempo cuando se hacen signo y valor de la vida de dos personas:

La cámara se detiene en su reloj de pulsera (Bacon) y con un zoom se muestran las manecillas girar frenéticamente en sentido contrario. Todo un símbolo. El tiempo real no puede volver atrás. También se consume y ha llegado a su fin. Es el tiempo de George, ya agotado. También el de su relación con Francis, el de él y el de la película. La historia ha terminado (Camarero, 2009, p. 401).

La aparición del cine a finales del s. XIX provocó un muy posible tambaleo en la mente de los espectadores ante la nueva manera de percibir el mundo y las impresiones que ello originaba. El público frente a la proyección de La llegada del tren a la estación de La Ciotat (L'arrivée d'un train à La Ciotat, Auguste y Louis Lumière, 1896) (F1) saltaba despavorido por miedo a ser arrollado por la cercanía de la locomotora. Tom Gunning, historiador de cine, no considera que este hecho se produjera de tal manera ya que el público de aquel tiempo "no era tan ingenuo como para confundir las imágenes con la realidad (...). Lejos de ser la credulidad, es la increíble naturaleza de la propia ilusión la que deja al espectador sin habla, se trata menos de la velocidad inminente del tren que de la fuerza del aparato cinemático" (Darley, 2002, p. 82). Esto nos lleva a concebir al dispositivo cinematográfico como un ente creador de imágenes que reproducen la realidad comparándose con ella, simulándola. Estas imágenes tratan de falsear la realidad, de travestirla, cuando se transfiguran "en un biombo de la realidad, a la que ocultan, como aquellos paisajes de cartón piedra que se erigían en los itinerarios que recorría Catalina de Rusia y que constituyeron una anticipación involuntaria de nuestra realidad virtual" (Gubern, 1996, p. 123). 


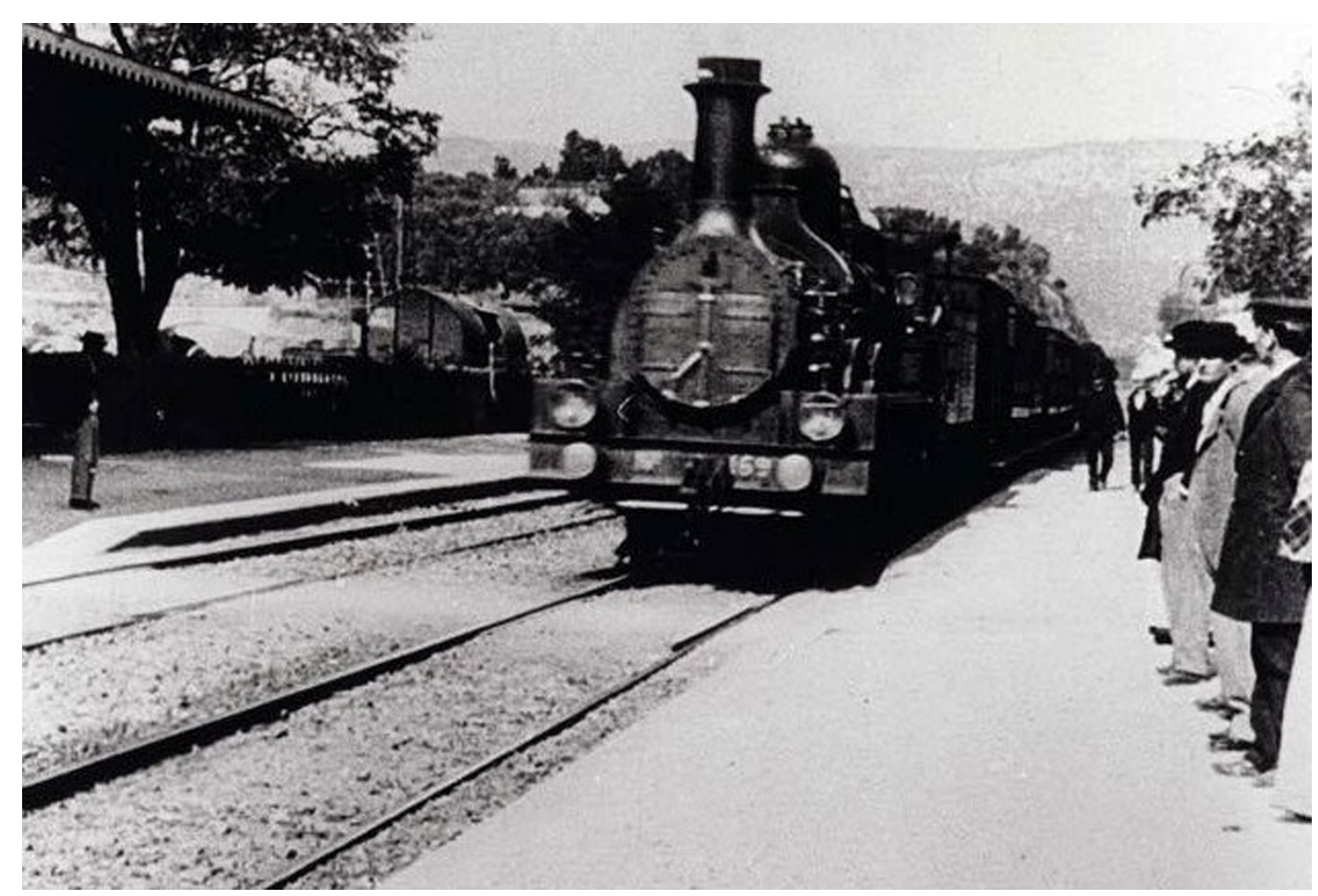

F1. La llegada del tren a la estación de La Ciotat, 1896. Auguste y Louis Lumière (http://laestaciondelfotogramaperdido.blogspot.com/2012/o9/el-cine-el-tren-y-lavida.html)

La simulación es sinónimo de superficialidad, de una ambivalencia semántica que se maneja con la mentira y la ilusión, en una separación directa de la realidad eliminando y revirtiendo todo signo de referencia valuable, y estudiando de manera exhaustiva las coordenadas cartesianas compaginándolas con nomogramas, sintagramas $\mathrm{u}$ organigramas -entre otros. Para Baudrillard y Calabrese más que un efecto de ficción es "un efecto de imitación de un fragmento del mundo, tanto en la sustancia como en el tiempo en que se da" (Baudrillard y Calabrese, 2014, p. 49). Será necesario un cotejo, una seducción, una simultaneidad mental de dos objetos comparables que reafirmen el artificio, el juego de las apariencias, lo que Baudrillard denomina como "abismo superficial" (Darley, 2002, p. 108) o como atestigua Deleuze "los simulacros son esos sistemas donde lo diferente se relaciona con lo diferente por medio de la misma diferencia" (Deleuze 2012, p. 440). En un análisis semántico este filósofo francés diferencia entre simular y disimular como dos términos antagónicos: "Disimular es fingir no tener lo que se tiene. Simular es fingir tener lo que no se tiene. Lo uno remite a una presencia, lo otro a una ausencia” (Baudrillard, 2005, p. 12). 
En el caso que nos compete, como es el cine, la opsis o visión es de vital importancia para que el simulacro se desarrolle en toda su extensión representativa y de significado, ya que un simulacro puede abarcar diversos tipos de lenguaje, no exclusivamente el visual, y como expresa Hans-Georg Gadamer debe exponer la profunda dimensión de la "no-distinción estética" (Gadamer, 1991, p. 78). La simulación comienza desde la implosión del sentido, en el preciso instante en el que la realidad desfallece y el vértigo de vernos avocados a este nos abruma. El hecho de intentar suspender la incredulidad y hacer creer son objetivos principales de este tipo de representación, que para Pascal Bonitzer “enfrenta al espectador con su deseo, es decir, con el deseo de que haya algo y no nada, al tiempo que le demuestra que algo y nada se dan de manera simultánea en la emergencia escandalosa del simulacro" (Bonitzer, 2007, p. 71).

Para crear ese espacio simulado es necesario dominarlo, lograr con la escenografía un acto comunicativo que nos dé las pautas para hacernos con el lugar, sentirlo como propio, identificarlo como nuestro. El simulacro nos adentrará en un terreno, donde las diferencias entre lo real y lo ficticio son indistinguibles, donde el referente se convierte en una realidad a la que se pretende desbancar y dejar como artificio, en un intento por ser más real que la propia realidad. El desconcierto y la confusión que provoca el choque de ambos mundos nos sumerge en un laberinto de espejos en el que hay que averiguar cuál de ellos es el real, y en un acto de ekística colocar al espectador en su lugar, ante la posible sensación de ausencia, de no-sitio, de estar perdido o abandonado, de ser ajeno, de anular la fantasía de inmersión. De ahí, que las experiencias incluso con el videoarte o el net art, donde nos transfiguramos en seres virtuales cuando nos convertimos en un avatar - por ejemplo-, hagan que la realidad incorpore nuevas formas de sí misma y en su pacto con el cine dé paso a "formas de representación que conjugan el trucaje con el montaje, la narración con el ensayo, la ficción con el documental, la imagen real con la animada, las dos y las tres dimensiones y, muy especialmente, la existencia de diversos mundos, superpuestos o paralelos” (Riambau, 2011, p. 145). Igualmente Jean-Louis Baudry conjuga el dispositivo cinematográfico con el empleado durante el sueño, al establecer analogías entre sus componentes: 
Estado del sujeto, (durmiente/espectador), alucinación que simula ser realidad (sueño/film), proyección de imágenes (oníricas/cinematográficas), etc. El modo de percepción común a ambos correspondería a la indistinción entre representación y percepción o, más bien, al de 'una representación dada como percepción que condiciona la creencia en la realidad del sueño' (Vila, 1997, p. $322)$.

Este creer o no creer que lleva implícito el simulacro nos lleva a ejemplos donde la imposibilidad del acto y gesto cinético nos envuelve para mitigar la artificiosidad de la realidad digital como en El club de la lucha (Fight Club, David Fincher, 1999) donde recorremos el interior del cerebro del protagonista hasta desembocar en su orificio bucal donde nos espera una pistola a punto de disparar, en Cómo ser John Malkovich (Being John Malkovich, Spike Jonze, 1999) en el que el protagonista encuentra un pasadizo para llegar hasta las entrañas de su propio cuerpo, o en Origen (Inception, Christopher Nolan, 2010) (F2) donde el espectador se introduce en las diferentes capas de los sueños, entre otros.

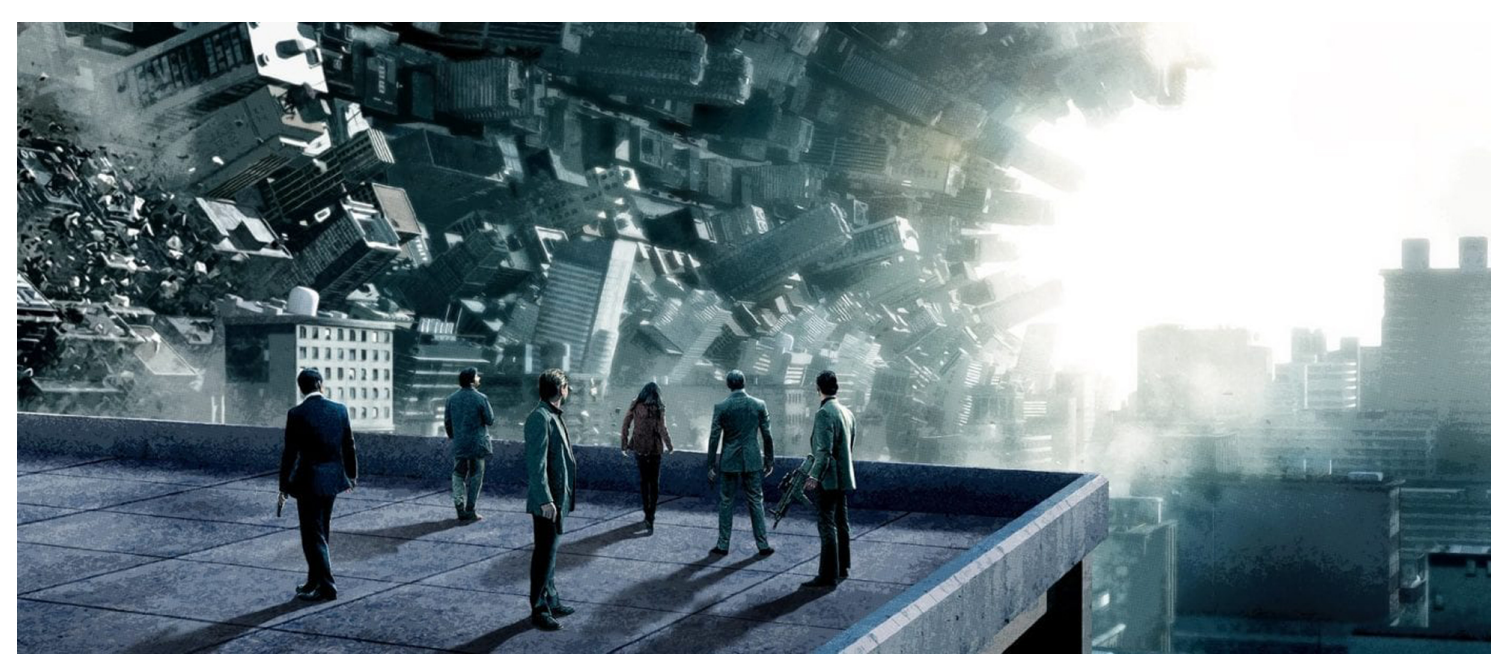

F2. Origen, 2010. Christopher Nolan (https://sextabutaca.com/origen-inception-de-christopher-nolan/)

\section{El juego como creación de una metarrealidad}

La simulación cinética lleva implícitas unas reglas que producen efectos sobre el espectador, y generan un tira y afloja entre ambos, conformándose una combinación de movimientos que provocan un determinado tipo de placer. Nos referimos al juego. Este término - “juego”- engloba multiplicidad de 
posibilidades ya sea de manera práctica (juegos a realizar física o mentalmente), de lenguaje (juegos de palabras), de significado (no jugar con algo como motivo reprochable), de conjunto (número de elementos) o de movimiento (juego entre dos piezas) -entre otros. De la taxonomía o clasificación del juego realizada por Roger Caillois (1986) extraemos:

(en los) juegos de Mimicry: (...) no predominan las reglas sino la simulación de una segunda realidad. El jugador escapa del mundo haciéndose otro. Estos juegos se complementan con la mímica y el disfraz. Son los juegos esencialmente de representación, por lo que son los que más se conectan con el arte y la expresividad de la cultura como manifestación artística. Juegos de Ilinx: se basan en buscar el vértigo, y consisten en un intento de aniquilar por un instante la estabilidad de la percepción y de inflingir a la conciencia lúcida una especie de pánico voluptuoso. En cualquier caso, se trata de alcanzar una especie de espasmo, de trance o de aturdimiento que provoca la alteración de la realidad con una brusquedad soberana (Salinas, 2010, p. 103).

En nuestro caso de estudio, los juegos de Mimicry, serían, por su adecuación, los idóneos para el cine y sus intenciones, así como los de Ilinx en su relación con la realidad virtual, realidad aumentada y las teorías del exceso creadas a partir de mundos digitales.

Por tanto el juego cinematográfico, con una ordenación estricta que marca su carácter y sus movimientos, como pura esencia de su existencia, debe afrontarse con la misma seriedad con la que está estructurado y hacer de su manifestación la práctica y puesta en escena de varios "jugadores". Participantes que se identifican como espectadores que han de adentrarse en el mismo sin esfuerzo aparente y sin una intencionalidad precisa, motivados por la atracción y fascinación del propio juego. Esta se constituye en un lugar donde el simulacro se confunde con la creencia como expone Gadamer: "En nuestro concepto del juego se deshace también la distinción entre creencia y simulación” (Gadamer, 1988, p. 147). Ya no se distingue entre la realidad vivida y la no-realidad efectista porque, al fin y al cabo, como declara Friedrich Schlegel “todos los juegos sagrados del arte no son más que imitaciones lejanas del juego infinito del mundo, de la obra de arte que eternamente se está haciendo a sí misma” - continúa Gadamer. Quizás, la afirmación de Jacques 
Ehrmann "Play, reality and culture are synonymus and interchangeable" [“Juego, realidad y cultura son sinónimos e intercambiables"] pudiera encajar perfectamente, aunque según Brian Edwards sería volver al homo ludens (Huizinga, 2012) y tratar al juego como algo esencialmente indefinible (Edwards, 1998: 22). Así, la imagen en el cine se convierte en simulación, en realidad irreal, que intenta ir más allá de la verdad fingida y de ser más que la metáfora de la metáfora; y encuentra en el simulacro y el juego la pareja ideal para conseguir sus objetivos, encadenarlos y revertir sus posibilidades en pos de un nihilismo que ensombrece cualquier atisbo de reacción del espectador, aunque consciente de sus capacidades, como en El juego (The Game, David Fincher, 1997). Sobre el juego señala Recio:

El nihilismo (se toma) como el fruto de toda determinación o fijación del ser que pretende ser más que una ficción, que un simulacro. (...) El fracaso del simulacro es solo tal para el que niega su origen azaroso. (...) Un simulacro, esto es, un juego de máscaras, no puede ocultarse. La máscara no puede pasar por otra cosa que por máscara. (...) En cuanto juego, no puede olvidarse que los jugadores saben que están jugando, dicho de otra manera el juego no puede pasar por otra cosa que no sea la ficción, la mentira, el engaño, la máscara, y esto no puede garantizar verdad alguna, ninguna correspondencia, porque siempre está en primer plano la duda, la sospecha de que lo que dice no se ajuste a su propio patrón (Recio, 2009, p. 24).

Este espectador, que denominábamos 'jugador', es el que interactúa con la proyección de la película, teniendo su propio juego en su mundo interpretativo mediante el cual suscita a que se produzca (el juego) ante sí mismo. Pero hay que tener en cuenta que dicho jugador debe competir en la misma categoría que el filme pues, como expresa Gadamer, "el juego posee un contenido de sentido que tiene que ser comprendido y que, por lo tanto, puede aislarse de la conducta de los jugadores. Aquí queda superada en el fondo la distinción entre jugador y espectador" (Gadamer, 1988, p. 153-154), que puede implicar el uso de la razón para desentrañar aquello que se propone. El hecho de comprender supone parte primordial para que el juego pueda desarrollarse por completo siendo un claro ejemplo de ello, el del ajedrez. El cine podría verlo como una partida entre proyección y espectador, como la realizada a vida o muerte en $E l$ 
séptimo sello (Det sjunde inseglet, Ingmar Bergman, 1957); la que reproducen Marcel Duchamp y Man Ray en Entreacto (Entr'acte, René Clair, 1924) (F3); la impresionante de tamaño gigante acaecida en Los viajes de Gulliver (The 3 Worlds of Gulliver, Jack Sher, 1960); o las piezas de movimientos destructivos que albergan a sus jugadores en Harry Potter y la piedra filosofal (Harry Potter and the Philosopher's Stone, Chris Columbus, 2001), entre otras.

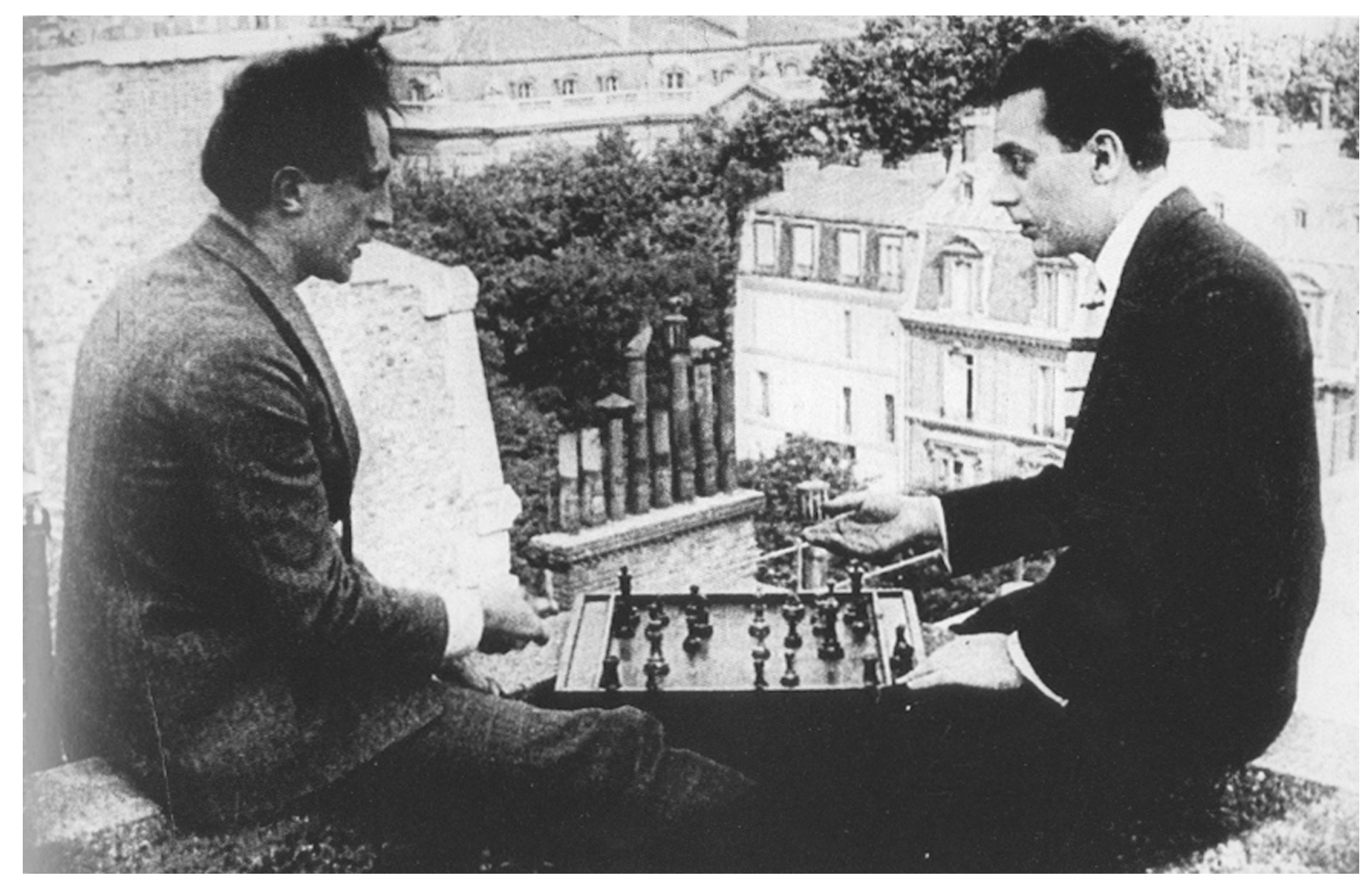

F3. Entreacto, 1924. René Clair

(https://revistafilosofiahoy.files.wordpress.com/2010/12/sin-tc3adtulo-1.jpg)

Todas las convenciones o acuerdos establecidos que se proponen entre el espectáculo y el público deben ofrecerse claramente para que pueda aceptarse su mecanismo y entenderse desde un inicio, como los carteles que mencionaban los lugares en el teatro de Shakespeare o los letreros de tiempo y espacio en el teatro de Brecht, por ejemplo, al más puro estilo como propone Philippe Amand: "Para mí son las reglas del juego, como cuando de niños que nos ponemos de acuerdo para hacer un juego y establecemos todo lo que se vale y lo que no se vale" (González, 2014, p. 45). En verdad, y siendo concluyentes como lo hace Andrew Darley, en el cine "en gran medida no resulta incorrecto decir que con lo que se juega es con el espectador" (Darley, 2002, p. 269). 
Este elegir reglas de consenso entre los participantes-jugadores nos puede trasladar al hecho de vivir, de habitar un mundo, que aunque primigeniamente parezcan inadvertibles están ya marcadas y preconcebidas como expone Eugene Fink: “El juego impera y gobierna de punta a cabo la entera existencia humana, y determina esencialmente su modo de ser - y también el modo de comprender humano del ser” (Fink, 1979, p. 115). Es un acto, llevado al término de vivencia obligada en el mundo, inconsciente de raíces intrínsecas, ya que como continúa Fink: "jugar es un hacer impulsivo, espontáneo fluyente, acción animada. Es, en cierto modo, en sí misma existencia móvil. Pero la movilidad lúdica no coincide con las otras formas de movimiento de la vida humana". No concuerda puesto que sus reglas no son las mismas, aunque puedan confluir en esencia, dado que jugar precisa de una puesta en escena estratégica y un equipo conceptual con la misión de disuadir el semblante de la trascendencia, si no el juego se reduce a una improvisación desprovista del círculo vicioso en el que se circunscribe.

Gilbert Boss, por su parte, diferencia entre lo liviano del juego creado y la seriedad del mundo real, declarando: "El juego es ligero porque se juega en una esfera limitada en la que todo le pertenece, mientras que lo serio es grave porque en sus faenas pesa todo el universo, que permanece, no obstante, oculto tras ellas" (Boss, 1979, p. 7). Creemos que somos dueños de una capacidad imaginativa y de un mundo que alcanza hasta nuestras propias delimitaciones, principalmente siendo niños, porque en ese momento de la vida cualquier cosa puede convertirse en un elemento para el juego. Este es el punto, el del juego, en el que el cine despliega todo su sentido, nos arroja a otras vidas, otros mundos y otras realidades. Nos invita a jugar, a asumir un patrón marcado y en el momento en el que decidimos entrar, pertenecemos al mismo.

Esta mezcla extraña de realidad e irrealidad produce un placer lúdico y, a su vez, "el sufrimiento-del-juego que es vivenciado placenteramente ocasiona una catarsis del alma” (Fink, 1979, p. 120). El discurrir de emociones, sobrevenidas a lo largo del período que lleva a cabo el juego, hace que nos sintamos inmersos dentro de la cooperatividad filme-espectador, creándose una metarrealidad que se produce en un viaje de ida y vuelta, en un 
intercambio, que exige un orden absoluto. Ya que, si no, cualquier trampa equivale a un despiste, a desconectar de la historia, a dejar de ser un jugador más, dado que el juego "no conoce propiamente la distancia entre el que juega y el que mira el juego" (Gadamer, 1991, p. 69), y aún más en el modelo actual de sociedad de excesos que nos lleva a "nuevas formas de contar historias mediante la jugabilidad, nuevos modos de interrelación juego-jugador" (García, 2020: p. 13) como en Black Mirror: Bandersnatch (David Slade, 2018) donde el propio espectador puede decidir el devenir de la película.

El ritmo y la armonía son necesarios dado que "oprime y libera, el juego arrebata, electriza, hechiza (...) es una lucha por algo o una representación de algo" (Huizinga, 2012, p. 33). Como representación tiene un comienzo y un final, y en el momento que el juego ha terminado, la ficción ha dejado de existir. Por ello, como expone Boss:

En el juego, el premio es entonces a la vez la meta de la acción y un simple medio cuyo fin es dicha acción. Dicho de otra manera, más que un fin real, el juego posee "blancos". Sin ellos, el arquero no tendría nada que apuntar, pero el verdadero fin del juego no reside en que la flecha sea clavada en el blanco, sino en la acción de apuntar (Boss, 1979, p. 14).

Llega ahora, a modo de resumen, el momento de preguntarnos: ¿Qué tienen en relación el simulacro y el juego? Disfrutan cooperando, por ser cómplices. El primero se disfraza para parecer otra cosa y no ser reconocido, el segundo recrea mediante diversos dispositivos todo un engranaje para que los jugadores no descubran el disfraz y lo tomen como la realidad misma. Como lo define Gadamer:

Juega a ser otro, pero solo en el sentido en el que uno juega algo en su vida práctica, esto es, en el sentido de aparentar algo, colocarse en una posición distinta y suscitar una determinada apariencia. Aparentemente el que juega de este modo está negando su continuidad consigo mismo. (Gadamer, 1988, p. 156)

Sobre el juego, declara: “(este) aparece entonces como el automovimiento que no tiene un final o una meta, sino al movimiento en cuanto movimiento, que indica, por así decirlo, un fenómeno de exceso, de la autorrepresentación del ser viviente" (Gadamer, 1991, p. 67). Este “fenómeno de exceso", del que habla, 
lo abordaremos más adelante. Aunque, previo a adentrarnos en ello, conozcamos más a fondo las creaciones virtuales y sus diferentes proyecciones y posibilidades que hacen del simulacro y el juego toda una dependencia de creencia continua.

\section{La imagen-exceso: hacia una hiperrealidad cinematográfica}

Erwin Panofsky señaló sobre el nacimiento del cine que no fue "una necesidad artística la que provocó el descubrimiento y el funcionamiento de una nueva técnica, fue una invención técnica la que provocó el descubrimiento y el funcionamiento de un nuevo arte" (Quintana, 2011, p. 9). Los cambios tecnológicos, acaecidos desde mediados del siglo XIX, fomentaron que el cine evolucionara desde el sonido y el color hasta una realidad intangible que desecha el soporte fotoquímico, así como hacia una progresiva digitalización de medios cuyo fin es la virtualidad perfecta. La relación y vinculación intrínseca con la imagen que mantiene dicha evolución marca una línea de pensamiento en continua progresión que indaga formas de escapar de la realidad y según Heidegger una "búsqueda de un camino que haga posible nuevas formas de pensar, de la relación con el ser y de comprensión del mundo" (Guerra, 1997, p. 138), de este modo el mundo se concibe como imagen. El paso del negativo a los datos informáticos supone una nueva dimensión para las imágenes cuestionando cualquier verdad que pretendan difundir, ya que la manipulación y modificación de sus datos queda en este mundo digital en entredicho y la relación que instituía con la realidad referencial provoca un cambio drástico de vinculación y en los oficios (en el cine) que la generan.

La imagen digital, infográfica o de síntesis se concibe como crucial para el cine comercial actual, y su evolución ha ido contribuyendo al desarrollo del simulacro y la creación del juego - en su relación con el espectador. Un simulacro que se adueña de la imagen digital y que ya no presenta reminiscencias de captura de huellas del mundo real y físico y que lo enuncia, según Siegfried Kracauer -con respecto al cine- como "la redención de la realidad física”; y según André Bazin como "un lenguaje (que permite) a los 
cineastas la creación de realidades sintéticas que pueden ser contempladas como realidades fotográficas" (Riambau, 2011, p. 15). Este proceso individual de discernimiento del mensaje se transforma a partir de una codificación colectiva que plantea una relación de retroalimentación entre cerebro, lenguaje y evolución.

Esta irrupción digital explora límites inabordables, fronteras insospechadas que relegan y hacen olvidar los ya tradicionales trucajes de vidrio pintados y decorados corpóreos exponiendo a la escenografía en un primer plano, de la capacidad imaginativa y creadora del artista en la pantalla. De igual manera, los efectos especiales también son aportados por esta nueva tecnología que contribuirá con tan diversas opciones como la clonación de personajes, la creación de criaturas virtuales, la captación de movimientos y expresiones humanas, o el morphing - entre otras. La transformación tecnológica desde los panoramas, pasando por el Cinemascope, el Cinerama o el Cineorama, hasta los formatos IMAX u Omnimax de sincronización de los movimientos de la butaca con lo expuesto en el filme, logran en el espectador la creencia de estar ocupando el lugar que está contemplando. De ahí, que los juegos de la realidad virtual consiguen estos efectos a partir de una copia demasiado perfecta, que imita la realidad, la desdobla, y entra en el umbral de la confusión y la creencia, no sabiendo (el espectador) si es el original en sí o su sombra. Gene Youngblood ya predecía en 1980: "La idea de realidad permanecerá total y definitivamente oscurecida cuando alcancemos la creación de una realidad artificial plenamente convincente en el interior de los sistemas de tratamiento de la información" (Riambau, 2011, p. 16). Sin lugar a dudas, la imagen es el fragmento de realidad que observamos y escrutamos, y al que exponemos a un esfuerzo mental durante la asimilación de la información, lo que han denominado Steve Aukstakalnis y David Blatner como "procesamiento consciente" (Aukstakalnis y Blatner, 1992, p. 40). Un proceso que debe pasar desapercibido para adentrarse en la realidad virtual e implicar una suspensión de la incredulidad en el espectador y que haya, como mencionan Bettettini y Colombo, una "disponibilidad a participar emocionalmente en lo que está sucediendo en el mundo virtual” (Bettettini y Colombo, 1995, p. 93). Por su parte, Jean Baudrillard declara que: 
(...) no se trata aquí de imitar, ni de duplicar, simular la realidad. En la realidad virtual no hay artificialidad, porque lo artificial copia o imita la realidad, sino un simulacro, donde la representación mediática precede y determina lo real, traza una nueva topografía del entorno percibido como realidad (Suárez, 2010, p. 78).

Gubern mantiene frente a esta posición lo siguiente:

La realidad virtual es una ilusión perceptiva que adquiere el estatuto de una pseudorrealidad, en el seno de una realidad que queda eclipsada por aquella. $Y$ de este modo desborda la vieja cultura de los simulacros, que tanto han inquietado a Baudrillard, la cultura de los artefactos imitativos clásicos, para penetrar en la cultura alucinatoria de la simulación, una simulación que incluye al propio sujeto y a su ubicación topológica en un espacio tridimensional fingido (Gubern, 1996, p. 180).

Este tipo de realidad aúna esfuerzos haciendo de su método inteligible una eliminación de barreras de lenguaje y comprensión conjunta, convirtiéndose en una nueva forma humana de interacción con datos informáticos mediante la visualización y manipulación de dispositivos.

La deshumanización del hombre por parte de las tecnologías quizás marque un antes y un después en la conformación del cine digital y del futuro, pero ahondemos ahora en las capacidades de un medio (el digital) que, haciendo uso del neobarroquismo, lo sublime, el exceso y la prepotencia de sus capacidades tecnológicas, pretende generar una hiperrealidad en el receptor que lo observa. Método que, hasta el momento, se ha granjeado el favor de millones de espectadores ante la espectacularidad de sus producciones e inventivas.

Kenneth J. Gergen denomina "multifrenia” (2006, p. 113) a las consecuencias de nuestra interacción con las "tecnologías de la relación”. Consiste en la sensación de vértigo a la que nos vemos abocados ante la infinidad de posibilidades y expectativas, generadas por este tipo de medios. El deseo entra a formar parte en esa ruptura entre el espacio y el tiempo, entrando a la exigencia del 'debo', 'quiero' y 'necesito' como factores intermediarios de la comunicación y las relaciones sociales en un reemplazo de la calidad por la cantidad. 
Este hecho que vemos ejemplificado en nosotros mismos si lo extrapolamos al mundo de las imágenes y del cine conecta perfectamente con esa multiplicidad, pluralidad y abundancia que muestran las creaciones virtuales escenográficas: "Ya no se trata de ver lo que la imagen muestra ni, mucho menos, de ver la imagen, sino de reconocer que el fondo de toda imagen es otra imagen, que nos encontramos ante un infinito carrusel de vertiginosos reemplazos" (Riambau, 2011, p. 17).

Este símil que acometemos entre la persona y las imágenes sintetizadas por ordenador llega a tal grado de cercanía que como expone Roland Barthes, constituye una "Falsificación, simultáneamente, de sí mismo, pastiche y fetiche irrisorio, que muestra su fisura y su sutura" (Darley, 2002, p. 183). Este afrontar el mundo de las imágenes cinematográficas como si recorriéramos mundos inexplorados, ha forjado para Jonathan Crary "un nuevo observador menos seguro de la fiabilidad de lo que ve y más consciente, por tanto, del carácter subjetivo de la visión” (López, 2004, p. 33). Ahí reside un cine hipermoderno del que hablan Gilles Lipovetsky y Jean Serroy, exponiendo tres características fundamentales: una dinámica de hiperbolización (con una estética extralimitada de proliferación vertiginosa y exponencial, denominada imagen-exceso); una hibridación (pluralidad y multiformidad en aumento del espacio-tiempo fílmico, llamada imagen-multiplejidad); y una autorreferencialidad (que conduce a una imagen-distancia) (Lipovetsky y Serroy, 2009, pp. 68-70) (F4).

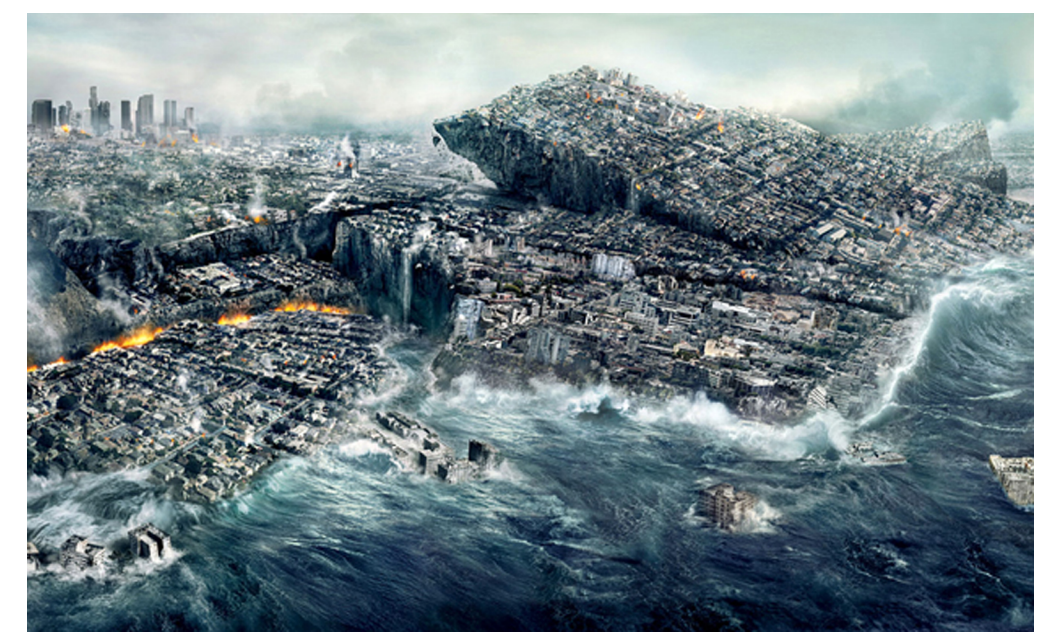

F4. 2012, 2009. Roland Emmerich (https://ponungeologentuvida.files.wordpress.com/2013/02/2012.jpg) 
La referencialidad que necesita el propio espectador encuentra su lugar en la realidad, que debe traspasar las fronteras del simulacro hiperestimulado del engaño visual y de su propia patafísica - al tratarse de algo inventado, un resultado imaginario. Un simulacro que se posiciona como ingente reclamo hiperrealista en primer término y como secuaz inseparable del ser, del existir por sí mismo. El espacio en el que se mueve es siempre en el aquí y ahora, para un momento determinado de una época en la confluencia del instante, convirtiéndose en un "cortocircuito fantástico: lo real es hiperrealizado. $\mathrm{Ni}$ realizado, ni idealizado: hiperrealizado. Lo hiperreal es la abolición de lo real no por destrucción violenta, sino por asunción, elevación a la potencia del modelo" (Baudrillard, 2005, p. 189).

Surge la hiperrealidad, un término abordado principalmente por Jean Baudrillard que, a modo de simulación desencantada, va constituyendo las imágenes de un mundo contemporáneo y de su imaginario, volatilizando la realidad con la que compite y alzándose como más real que lo real. Así, lo sugiere Quintana cuando recorre el libro El crimen perfecto (1995) de Baudrillard:

La realidad para Baudrillard es un mundo permanentemente escenificado en que la proliferación de pantallas no hace más que crear auténticos trampantojos, hasta generar nuevas experiencias entendidas como la manifestación de una hiperrealidad que ha suplantado los procesos sensibles. (Quintana, 2011, p. 90)

Quizás esta suplantación, a la que nos expone la hiperrealidad, nos lleva a una metarrealidad que a nuestro parecer es lo que las imágenes de síntesis y el cine digital nos proponen y nos hacen adentrarnos en una nueva espacialidad, que da forma a lo intangible. Esta (hiperrealidad) se nos presenta como "un continuum [...] dos realidades deslizándose una sobre otra, diferentes pero íntimamente interrelacionadas [...] activando una relación de identidad como representaciones de una misma y única realidad que nunca ha existido" (Lanza Vidal, 2018: p. 159), como sucede en el Matte Painting entre la pintura-pintura y su homónima digital. Es precisamente un ejemplo de creación de dos realidades que se fusionan para generar una nueva, en este caso, sobre una 
estructura geométrica, fehaciente y con posibilidades creativas infinitas. Por tanto, las teorías de Martin Jay en torno a los regímenes escópicos (cartesiano, empirista y barroco), nos sirven de guía para ello. El primero, cartesiano, asume una posición de punto de vista fijo y único, sin comprometerse con el objeto que mira, considerando "el espacio geométricamente isotrópico, rectilíneo y uniforme" (López, 2004, p. 27). El segundo, empirista, exalta la existencia previa del mundo orientando su ojo hacia la observación "sobre la superficie fragmentaria, detallada y profusamente articulada de un mundo que prefiere describir antes que explicar" (Balcarce, 2006). Y el tercero, barroco, se caracteriza por lo múltiple, lo disperso, estando "fascinado por la ilegibilidad de la realidad a la que representa. Esto explica que se disfrace con imágenes deslumbrantes y desorientadoras, extrasilentes, (...) y que apueste por los múltiples puntos de vista, la asimetría, el trampantojo, las sombras” (López, 2004, pp. 28-29). La mirada barroca está ligada con el posmodernismo, que no es una mirada inocente al arrastrar patrones culturales y en palabras de Jay: "Si algo enseña el posmodernismo es a desconfiar de las perspectivas únicas, las cuales, como los grandes relatos, proporcionan explicaciones totalizadoras de un mundo demasiado complejo para ser reducido a un punto de vista unificado” (Balcarce, 2006), de ahí la hipertrofia actual de lo visual.

Los paisajes de síntesis que colman las pantallas de nuestros cines se han adueñado de esta línea barroca saturando la mirada del espectador en cuanto a la oscuridad de lo vago unido a destellos de luz dorada con estruendosa capacidad escenográfica. Un gusto en busca del más allá de los límites, de lo inalcanzable, que Omar Calabrese denomina como Neobarroquismo, que "consiste en la búsqueda de formas, en su valorización, en la que asistimos a la pérdida de la integridad, de la globalidad, de la sistematización ordenada a cambio de la inestabilidad, de la polidimensionalidad, de la mutabilidad" (Calabrese, 1994, p. 12). Este paisajismo neobarroco tiende a lo excesivo, lo laberíntico, lo apocalíptico, la reiteración de patrones, incluso se extiende hacia la saciedad, la ansiedad, según Michael Heim, como estado sensorial de un espectador abrumado (López, 2004, p. 92). La mirada se desborda, queda apresada por el poder del exceso y sustituye a un espectáculo que se 
caracterizaba por el ilusionismo y la teatralidad, por caracteres más hiperbolados como "la obscenidad, que implica transparencia, pornografía o exceso de visibilidad. Más que individuos alienados por el espectáculo, Baudrillard ve a gente atrapada en una fascinación estática y en actos narcisistas de juego aleatorio" (Darley, 2002, p. 289). Este exceso se lleva hasta el extremo de la vastedad, el gigantismo, la desproporción, la potencia de la naturaleza y de los espacios cuando es inabarcable y en la que su suficiencia, dominio y superioridad tan aplastante de atractivo crea, como lo denomina Baudrillard, un "vértigo táctil" (Baudrillard y Calabrese, 2014, p. 11). De ahí que Baldine Saint Girons exprese ese sentimiento de admiración y estupor:

Las perspectivas que ofrece un campo abierto, un vasto desierto, un enorme macizo montañoso, elevadas rocas, inmensos precipicios, o una amplia extensión de agua, que no nos estremece solo por su novedad o por la belleza de los aspectos, sino por esa especie de ruda magnificencia que aparece en varias obras de la naturaleza (Girons, 2008, p. 159).

Una sensación que se asemeja al asomarse, pongamos como ejemplo, al Gran Cañón del Colorado. La magnificencia del lugar intensifica "el tipo de sensación que en los siglos XVII y XVIII se vino a llamar 'lo sublime', es decir, la naturaleza a una escala superior a las dimensiones humanas acostumbradas en la llanura: un territorio emocionante, casi terrorífico" (Hockney, 2011, p. 140) o donde "la naturaleza remite a la instancia creadora en sí misma, lo no visible se manifiesta a través de lo visible, apelando a una comunicación adánica con el Creador” (Lanza, 2019, p. 251).

Este término de "lo sublime" ha sido abordado por Immanuel Kant, Edmund Burke y Friedrich Hegel. Kant lo describe como el "resultado de un conflicto entre facultades (...) produciéndose por medio del sentimiento de una suspensión momentánea de las facultades vitales” (Aullón de Haro, 2006, p. 194). A pesar de ello, se adentra a definirlo de manera más pormenorizada:

Lo sublime presenta a su vez diferentes caracteres. A veces le acompaña cierto terror o también melancolía, en algunos casos meramente un asombro tranquilo, y en otros un sentimiento de belleza extendida sobre una disposición 
general sublime. A lo primero denomino lo sublime terrorífico, a lo segundo lo noble, y a lo último lo magnífico (Kant, 2003, pp. 3-4).

Burke, por su parte, define el efecto que produce (lo sublime) en la mente como el asombro, mientras que la admiración o la reverencia son efectos de menor grado. Por ello, expresa: "El asombro es un estado del horror, quedando la mente tan llena de su objeto, que no puede reparar en ninguno más, ni en consecuencia razonar sobre el objeto que la absorbe. De ahí nace el gran poder de lo sublime, (...) nos arrebata mediante una fuerza irresistible" (Aullón de Haro, 2006, p. 104). Este estado del horror es fuente de lo sublime ya que “produce la emoción más fuerte que la mente es capaz de sentir” (Burke, 2005, p. 66). Mientras que para Hegel lo sublime es:

(...) esa disimetría entre mundo inteligible y apariencia fenoménica (...) es una suerte de incapacidad de objetivar el ideal defecto mundano unido a un exceso de abstracción de la idea del valor (...) en el intento de expresar el infinito (siendo, a su vez) testimonio de una impotencia de la forma para acoger lo absoluto, impotencia que no es trágica, en cuanto que presupone una relación no comunicativa, no mediada, abstracta y accidental, entre lo absoluto y lo fenoménico. Lo sublime es el canto del hombre en el desierto: pura verticalidad, sin mediación histórica, sin conflicto, por tanto, sin tragedia (Carchia, 1994, pp. 124-126).

Hegel refleja que es un acto no comunicativo, y es de remarcar esa negativa pues no se establece relación entre ambas partes puesto que la imagen existe por sí misma y no espera respuesta del espectador. Este obtendrá ciertos impulsos o sentimientos que no puede devolver a esa sublimidad, a esa creación aparentemente inherente sin capacidad de interrelación, y que como presencia jamás se podrá hacer realidad. Pedro Aullón del Haro propone las causas de la sublimidad y lo sublime en torno a tres esferas:

1) la de la naturaleza y el mundo, incluyendo en la naturaleza al ser humano y sus instintos; 2) la intuición-contemplación, que es fuente de la visión y de la trascendentalidad de espíritu; y 3) la razón-voluntad, que es fuente de fuerza y también posee capacidad trascendental, pero no de esencial proyección espiritualista (Aullón de Haro, 2006, p. 195). 
Este laberinto de realidades ocultas, de paisajes virtuales con estructura geométrica, de naturalezas increíbles (F5) que maravillan al ojo, de espacios que obnubilan la experiencia vivida por el ímpetu de sentir lo que son, nos conducen, como menciona Paul Virilio, a experiencias "que por culpa de las tecnologías estamos perdiendo el propio cuerpo en aras del cuerpo espectral y el mundo propio en aras del mundo virtual” (Suárez, 2010, p. 116). Quizás sea nuestra descripción actual, quizás sea la misma excitación de otros períodos con elementos distintos, solo que contada desde otra perspectiva.

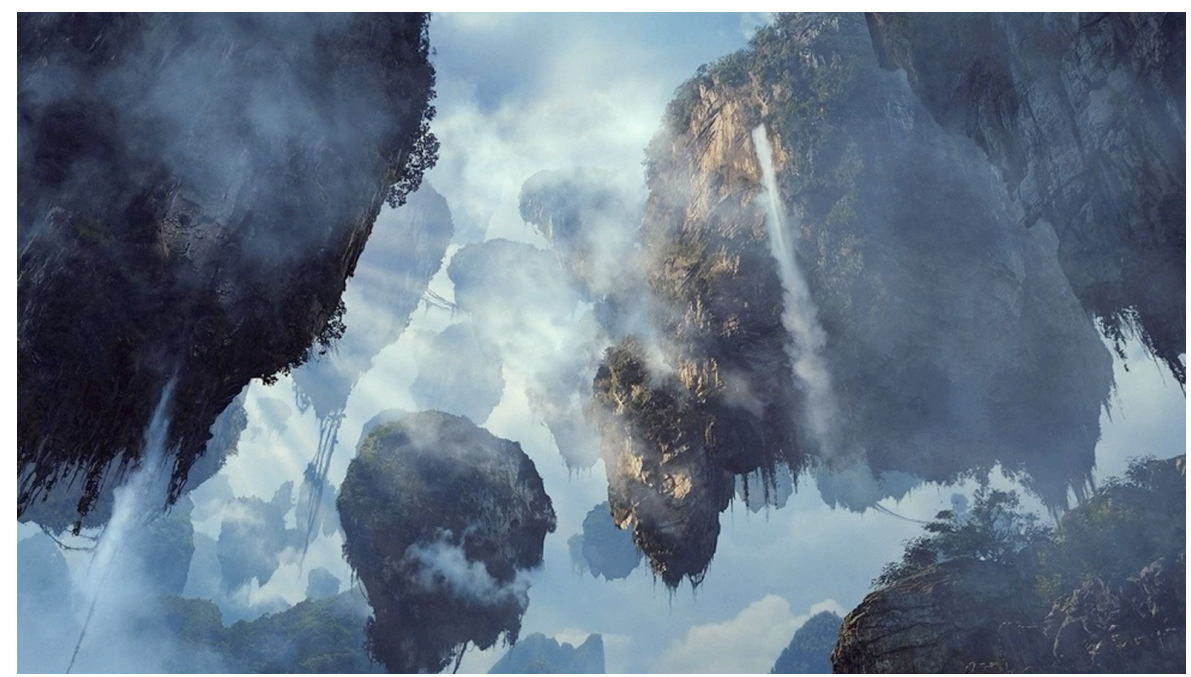

F5. Avatar, 2009. James Cameron (https://www.pymovie.tv/pelicula/avatar-143/)

Sin embargo, tal despliegue tecnológico digital en el cine tiene limitaciones cuando trata de simular hiperrealidades antropomórficas. Como ya se ha argumentado, la unión de simulacro y juego persigue imbuir al espectador en una escenografía hiperespectacular para hacerle partícipe del desarrollo del filme. Pero, cuando la recreación hiperrealista de personajes humanos no provoca esa misma respuesta en el observador se produce un distanciamiento de la pantalla, denominado Uncanny Valley (Masahiro Mori, 1970). Para el experto en robótica japonés, el valle inquietante surgía cuando el espectador experimentaba reacciones emocionales turbadoras al enfrentarse a robots o creaciones androides que trataban de conseguir un nivel de aproximación hiperrealista en expresiones faciales y movimientos corporales. En 2005, tras el estreno de Polar Express (The Polar Express, Robert Zemeckis, 2004), comienza a utilizarse el término aplicado a los diseños de personajes humanoides $3 \mathrm{D}$ que provocan extrañeza en el espectador, con la consiguiente 
pérdida de interés por lo narrado. Es precisamente en el intento de lograr un exceso hiperrealista antropomórfico cuando deviene la falta de credibilidad del receptor por las imágenes que observa, como sucede en Tin Toy (John Lasseter, 1988) y Final Fantasy: La fuerza interior (Final Fantasy: The Spirits Within, Hironobu Sakaguchi, 2001). A este respecto, William Poundstone expone que:

Esa es la idea de que los simulacros no-tan-perfectos de la forma humana, creen una sensación de extrañeza o repulsión. (...) En algún lugar entre lo humano y lo humanoide, las cosas se ponen raras. Estas semejanzas imperfectas (...) son mucho menos aceptadas que los menos perfectos (Poundstone, 2012).

Esta delgada línea entre el punto álgido de creencia o la caída inminente al fondo del valle inquietante se observa paradójicamente, y de manera "inexplicable", en títulos que cuentan con avances tecnológicos muy desarrollados, a saber: Beowulf (Robert Zemeckis, 2007) (F6) y Tron: Legacy (Joseph Kosinski, 2010) - entre otros. De ahí que Esteve Riambau se pregunte “¿de qué sirve todo ese esfuerzo si el espectador no deja de tener la impresión de asistir a un teatro de marionetas en el que todo cuanto se ha conseguido es que las cuerdas que las mueven sean invisibles?” (Riambau, 2011, p. 95).

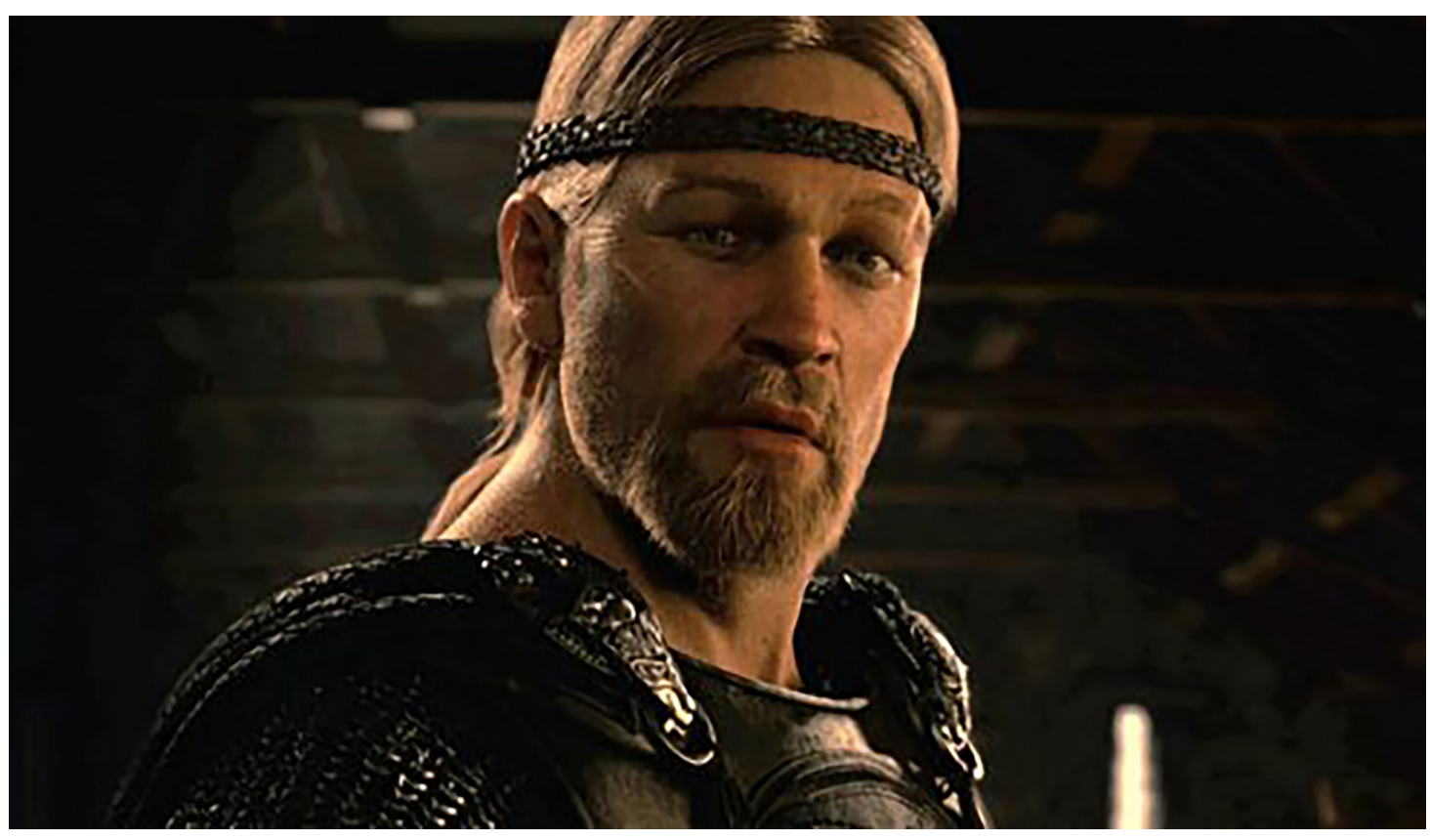

F6. Beowulf, 2007. Robert Zemeckis

(http://blogs.20minutos.es/ezcultura/2007/11/24/beowulf-craatica-puro-y-duroentretenimiento/) 
Ante la problemática de caer en el valle inquietante, los desarrolladores de $3 \mathrm{D}$ aplican estrategias a la imagen para eludir la caída. Un reto conseguido en Rogue One: una historia de Stars Wars (Rogue One: A Stars Wars Story, Gareth Edwards, 2016). Mediante el uso de un sistema informático (deepfake) que estudia un mismo rostro por medio de multitud de fotografías, siendo capaz de sustituir la del vídeo original por la analizada, se logra traer a la pantalla a Peter Cushing (el malvado Moff Tarkiny) fallecido en 1994 y a Carrie Fisher (la Princesa Leia) quien murió en 2016. No obstante, no son muchas las superproducciones que logran salvar este problema. La recreación de Baby Nezha en League of Gods (Vernie Yeung y Koan Hui, 2016) aún mantiene esta limitación. Por tanto, habrá que seguir esperando a próximos futuros para constatar cómo el valle inquietante es superado y se integra de manera natural en la imagen-exceso.

\section{Conclusiones}

A lo largo del presente estudio, centrado en el impacto que la imagen-exceso cinematográfica ejerce sobre el espectador, hemos constatado que el despliegue de imágenes hiperespectaculares, nacido de la pantalla de cine, puede suponer (para el receptor pasivo en la butaca, activo mentalmente) una vía para entender el modelo de sociedad "hipermoderna" en la que actualmente se vive. Sociedad de excesos determinada por el hiperconsumo, la hipercomunicación y el liberalismo cultural, político y económico. Una imagen-exceso que busca sorprender al receptor y catapultarlo a una nueva realidad, generando una sensación de atracción hacia la pantalla, que es por lo que lucha su verdadero cometido: hacer de su ardid el punto de inflexión entre la realidad y la hiperrealidad. Sumado a lo anterior, nuestro estudio arroja tres conclusiones principales, las cuales no cabría entenderlas con un sentido unívoco o normativo. La primera presenta a la imagen cinematográfica como un reclamo para el ojo humano donde el simulacro despliega todas sus posibilidades, camuflándose para hacer creer (al espectador) de su existencia, desviando a la realidad a un segundo plano. Esto se consigue gracias a que el simulacro desdibuja las diferencias entre lo real y lo ficticio para que no 
puedan ser distinguibles, algo que sucede cuando el referente se convierte en una realidad con el propósito de ser más real que la propia realidad. La segunda conclusión subraya el papel que ejerce el juego para adentrarse en la mente del espectador; es a través de su alianza con el simulacro como se forja e impone sus reglas en la estrategia de suspensión de la incredulidad y la inmersión en una metarrealidad virtual (por parte del “jugador” - el receptor). Mediante la predisposición del jugador a participar, el juego va tejiendo una red de puntos de referencia en el mundo a habitar (el virtual), situándolo en el contexto y haciéndolo suyo para su control con el fin de evitar las alusiones al mundo (real) - el que se encuentra fuera de la película. La tercera conclusión expone cómo las creaciones virtuales escenográficas que exceden lo hiperreal son el pretexto de atracción, que generan el simulacro y el juego, para hacer que el punto de partida y de llegada sea el mismo: la imagen. Este hecho se produce a raíz de la grandilocuencia y fascinación que provocan en el espectador estas creaciones digitales, ya que son el motivo por el cual son seducidos y cautivados a modo de hipnotización. Momento que aprovechan el simulacro y el juego para terminar de atrapar al receptor y desviar su atención de la realidad. A pesar de ello, y en cuanto a las creaciones antropormórficas, se remarca la importancia de la teoría del valle inquietante puesto que influye en la atención del espectador si la superproducción quiere lograr su inmersión completa en la película o, por el contrario, se generará un sentimiento de rechazo que lo separará de la pantalla. En suma, la imagen-exceso nos conduce por caminos de realidades superpuestas, aunque dependen del efecto que produzcan y del ojo que las observe.

\section{Referencias bibliográficas}

Aukstakalnis, S.; Blatner, D. (1992). El espejismo de silicio: arte y ciencia de la realidad virtual. Barcelona: Página Uno.

Aullón de Haro, P. (2006). La sublimidad y lo sublime. Madrid: Verbum.

Balcarce, L. (2006). Martin Jay y la hipertrofia visual. Poder limitado. [Consulta 20 de febrero de 2017]. Disponible en: http://blogs.periodistadigital.com/poderlimitado. php/2006/o8/23/martin-jay-y-la-hipertrofia-de-lo-visual

Baudrillard, J. (2005). Cultura y simulacro. Barcelona: Kairós. 
Baudrillard, J. y Calabrese, O. (2014): El trompe-l'œil. Madrid: Casimiro.

Bettettini, G.; Colombo, F. (1995). Las nuevas tecnologías de la comunicación. Barcelona: Paidós.

Bonitzer, P. (2007). Desencuadres: cine y pintura. Buenos Aires: Santiago Arcos.

Boss, G. (1979). Juego y filosofía. [Consulta 14 de febrero de 2017]. Disponible en: http://www.bdigital.unal.edu.co/30370/1/29175-104796-1-PB.pdf

Burke, E. (2005). Indagación filosófica sobre el origen de nuestras ideas acerca de lo sublime y de lo bello. Madrid : Alianza.

Calabrese, O. (1994). La era neobarroca. Madrid: Cátedra.

Camarero, G. (2009). Pintores en el cine. Madrid: JC.

Carchia, G. (1994). Retórica de lo sublime. Madrid: Tecnos.

Darley, A. (2002). Cultura visual digital: espectáculo y nuevos géneros en los medios de comunicación. Berconona: Paidós.

Deleuze, G. (2012). Diferencia y repetición. Buenos Aires: Amorrortu.

Edwards, E. (1998). Theories of Play and Postmodern Fiction. New York: Garlad Publishing.

Fink, E. (1979). Fenómenos fundamentales de la existencia humana. [Consulta 22 de enero de 2017]. Disponible en: http://www.cristobalholzapfel.cl/traducciones/FINK_fenomenos_ fundamentales.pdf

Gadamer, H. G. (1988). Verdad y método. Salamanca: Ediciones Sígueme.

Gadamer, H. G. (1991). La actualidad de lo bello. Barcelona: Paidós.

García Oltra, A. (2020). La revolución de los píxeles. Arte y videojuegos en un mundo digital. Revista Eviterna, (7), 88-102. Disponible en: https://doi.org/10.24310/Eviternare.voi7.8382

Gergen, K. J. (2006) El yo saturado. Dilemas de identidad en el mundo contemporáneo. Barcelona: Paidós.

Girons, B. (2008). Lo sublime. Madrid: A. Machado Libros.

González, X. (2014). Manual práctico de diseño escenográfico. México, D.F.: Toma, Ediciones y Producciones Escénicas y Cinematográficas: Paso de Gato.

Gubern, R. (1996). Del bisonte a la realidad virtual: la escena y el laberinto. Barcelona: Anagrama.

Guerra, R. (1997). Filosofía y fin de siglo. México: Universidad Nacional Autónoma de México.

Hockney, D. (2011). David Hockney: el gran mensaje / conversaciones con Martin Gayford. Madrid: La Fábrica Editorial.

Huizinga, J. (2012). Homo Ludens. Madrid: Alianza Editorial. 
Kant, I. (2003). Lo bello y lo sublime. [Consulta 22 de enero de 2018]. Disponible en: http://www.biblioteca.org.ar/libros/89507.pdf

Lanza Vidal, D. (2018). Relación simbiótica entre pintura y cine en el matte painting. Fotocinema. Revista científica De Cine Y fotografía, (16), 153172. https://doi.org/10.24310/Fotocinema.2018.voi16.4089

Lanza, D. (2019). Sobre la significación en la representación paisajística del "matte painting" cinematográfico. Propuesta para una clasificación. Arte, $\begin{array}{llll}\text { Individuo } Y & \text { Sociedad, } & \text { 31(2), }\end{array}$ https://doi.org/10.5209/ARIS.58668

Lipovetsky, G.; Charles, S. (2014) Los tiempos hipermodernos. Barcelona: Anagrama.

Lipovetsky, G.; Serroy, J. (2009). La pantalla global: cultura mediática y cine en la era hipermoderna. Barcelona: Anagrama.

López Silvestre, F. (2004). El paisaje virtual: el cine de Hollywood y el neobarroco digital. Barcelona: Biblioteca Nueva.

Poundstone, W. (2012). The Uncanny Valley (Battle of the Wax Museums). [Consulta 25 de marzo de 2012]. Disponible en: http://blogs.artinfo.com/lacmonfire/tag/uncanny-valley/

Quintana, A. (2011). Después del cine: imagen y realidad en la era digital. Barcelona: Acantilado.

Recio Fernández, E. (2009). El juego: un planteamiento filosófico. A Parte Rei, Revista de Filosofía (66). [Consulta 27 de enero de 2016]. Disponible en: http://serbal.pntic.mec.es/AParteRei/recio66.pdf

Riambau, E. (2011). Hollywood en la era digital: de Jurassic Park a Avatar. Madrid: Cátedra.

Salinas Quintana, P. (2010). El juego como fenómeno fundamental existencial humano (consideraciones desde la filosofía y la psicología del arte). Contextos, Estudios de Humanidades y Ciencias Sociales (24), 97-113.

Suárez, J. I. (2010). Escenografía aumentada: teatro y realidad virtual. Madrid: Fundamentos.

Vila, S. (1997). La escenografía: cine y arquitectura. Madrid: Cátedra. 